\title{
CUIDADOS DE ENFERMAGEM NA ADMINISTRAÇÃO DE MEDICAMENTOS IMUNOSSUPRESSORES NO TRANSPLANTE DE FÍGADO: REVISÃO DA LITERATURA
}

\author{
Nursing care on immunosuppressive drugs administration on liver transplantation: \\ literature review
}

Karina Dal Sasso-Mendes, Renata Cristina de Campos Pereira Silveira, Patrícia Abrahão Curvo, Cristina Maria Galvão

\begin{abstract}
RESUMO
Objetivo: Buscar as evidências disponíveis na literatura sobre a administração de medicamentos imunossupressores, com enfoque no cuidado de enfermagem no transplante de fígado. Método: A revisão integrativa da literatura foi o método de pesquisa utilizado. Para a realização da busca eletrônica, foi utilizada a Internet para acessar as bases de dados MEDLINE e CINAHL. Os descritores utilizados foram: agentes imunossupressores, cuidados de enfermagem e transplante de fígado. Os critérios de inclusão dos artigos selecionados foram: artigos que retratam a administração de medicamentos imunossupressores no transplante de fígado publicados no período de 1988 a 2008 e artigos no idioma inglês, português e espanhol. Foi selecionada uma amostra final de oito artigos Resultados: Além da administração dos medicamentos, a enfermagem é responsável pela monitorização dos resultados, prevenção de complicações e ensino aos pacientes sobre o uso de imunossupressores. A ciclosporina e o tacrolimus são indicados como tratamento profilático da rejeição de órgãos transplantados e no tratamento da rejeição crônica. Conclusão: A administração de medicamentos no transplante de fígado envolve não somente a administração dos fármacos em si, mas também um processo de educação em saúde, que permite aos pacientes e familiares a implementação correta da terapia medicamentosa no domicílio com o menor risco possível.
\end{abstract}

Descritores: Cuidados de Enfermagem; Transplante de Fígado, Imunossupressores.

Instituição:

Escola de Enfermagem de Ribeirão Preto da Universidade de São Paulo / Centro Colaborador da Organização Mundial da Saúde para o desenvolvimento da pesquisa em enfermagem - Ribeirão Preto / SP - Brasil

Correspondência:

Karina Dal Sasso Mendes

Avenida Bandeirantes, 3900 - Monte Alegre - CEP 14040-90 - Ribeirão Preto / SP - Brasil

Fone: (16) 36023467 Fone/Fax: (16) 36108543

E-mail: dalsasso@eerp.usp.br

Recebido em: 28.10 .2007

\section{INTRODUÇÃO}

A administração de medicamentos é uma das importantes funções que os enfermeiros envolvidos em programas de transplante de fígado realizam no período perioperatório. Envolve não somente a administração dos fármacos em si, mas também um processo de educação em saúde, que permite aos pacientes e seus familiares a implementação correta da terapia medicamentosa no domicílio com o menor risco possível, principalmente em relação à administração de imunossupressores. ${ }^{1}$

Um dos fatores que permitiu um aumento da expectativa de vida após o transplante de fígado foi o surgimento de medicamentos imunossupressores no combate à rejeição do órgão transplantado, tais como a ciclosporina e o tacrolimos, amplamente utilizados no mundo. Desse modo, é de suma importância que os enfermeiros que realizam cuidados de enfermagem em programas de transplantes de fígado tenham o conhecimento sobre a indicação, mecanismos de ação, vantagens e desvantagens, vias de administração, efeitos colaterais e cuidados necessários, quanto ao uso dessa terapêutica. ${ }^{2,3}$

Desse modo, o objetivo do presente estudo foi buscar as evidências disponíveis na literatura sobre a administração de medicamentos imunossupressores, com enfoque no cuidado de enfermagem no transplante de fígado. 


\section{MÉTODO}

Para a elaboração da revisão integrativa foram percorridas as seguintes etapas: identificação do tema, amostragem ou busca na literatura, extração dos dados dos estudos incluídos, avaliação dos estudos, interpretação dos resultados e a síntese do conhecimento ou apresentação da revisão integrativa., ${ }^{4}$

A pergunta norteadora da revisão consistiu em: quais os cuidados de enfermagem na administração de fármacos imunossupressores no transplante de fígado?

Para a seleção dos artigos incluídos na revisão foi utilizada a internet, para acessar as bases de dados on-line: Medical Literature Analysis and Retrieval Sistem (MEDLINE) e Cumulative Index to Nursing and Allied Health Literature (CINAHL), por meio das palavras-chave: cuidados de enfermagem, transplante de fígado e imunossupressores. Para reduzir os vieses durante a busca dos artigos foram utilizadas as palavras-chave contempladas no Medical Subject Headings (MeSH) e na List of Topical Subheadings do CINAHL Information Systems.

Os critérios de inclusão determinados foram: artigos que retratam o cuidado de enfermagem na administração de imunossupressores no transplante de fígado, publicados no período de 1988 a 2008 nos idiomas português, inglês e espanhol. Realizamos a leitura do título e do resumo dos 19 artigos identificados frente à pergunta norteadora e os critérios de inclusão adotados e selecionamos uma amostra final de oito artigos que foram analisados na íntegra. A extração dos dados dos artigos foi feita com o auxílio de um instrumento de coleta de dados elaborado pelos autores.

\section{RESULTADOS E DISCUSSÃO}

Em 1972, a ciclosporina foi extraída do fungo Tolypocladium inflatum Gams, mas só foi liberada para uso clínico a partir de 1983. É indicada como profilaxia para rejeição de órgãos transplantados (principalmente fígado, rins e coração) e para o tratamento da rejeição. Em 1994, o tacrolimos (também chamado Prograf ou FK 5506) recebeu aprovação do Food and Drug Administration (FDA) para ser utilizado comercialmente para o tratamento da rejeição no transplante de fígado. Foi extraído do fungo Streptomyces isukubaensis, existente unicamente no Japão. Ambos os medicamentos são combinados com corticosteróides. ${ }^{3,6,7}$

O mecanismo de ação da ciclosporina e o do tacrolimos são semelhantes e envolvem a inibição da ativação das células T, que é reversível com a descontinuidade do uso do imunossupressor. Quando ciclosporina ou tacrolimos está presente, ela atravessa a membrana plasmática das células $\mathrm{T}$ e se liga aos receptores citoplasmáticos. O complexo resultante receptor-ligante é um potente inibidor de calcineurina. Essa inibição da calcineurina previne a ativação das células $\mathrm{T}$ e a transcrição dos genes responsáveis pela mobilização do sistema imune para rejeição de órgãos. ${ }^{3,7}$

A ciclosporina pode ser administrada pelas vias endovenosa (EV) e oral. Quando administrada EV, deve ser diluída com solução salina ou de dextrose antes de sua administração. A solução oral pode ser misturada com leite ou suco de frutas, imediatamente antes de ser administrada. Os principais efeitos colaterais são hirsutismo, tremores, prejuízo da função renal, prejuízo da função hepática, hipertensão, hipercalemia, distúrbios gastrintestinais, retenção de líquidos e hiperplasia gengival. Sua absorção no intestino é dependente da presença de bile; desse modo, pacientes que realizaram reconstrução biliar apresentam com freqüência uma diminuição da absorção da ciclosporina oral. ${ }^{7}$

O tacrolimos também está disponível para administração oral e EV. O efeito colateral mais comum associado ao seu uso é o tremor de extremidades; outros efeitos colaterais freqüentemente observados são: necrose arterial, prejuízos dos rins e fígado, e indução ao estado diabético. Tal medicamento não está associado com hiperplasia gengival e hirsutismo. Quando ingerido com alimentos, apresenta diminuição de sua absorção no intestino., 7,8

A administração EV da ciclosporina e do tacrolimos deve ser supervisionada pelo enfermeiro. Esses medicamentos podem ser diluídos em solução salina estéril ou solução de dextrose 5\%. Nos primeiros 30 minutos da infusão e em intervalos subseqüentes, o enfermeiro deve avaliar sinais e sintomas de anafilaxia. A solução oral da ciclosporina não pode ser refrigerada e deve ser utilizada dentro de dois meses, após aberto o frasco. Alguns pacientes não suportam o sabor da ciclosporina (base de óleo de oliva), podendo assim ser diluída em bebidas, tais como leite, leite com chocolate e suco de frutas cítricas. Entretanto, deve ser evitada sua diluição com suco de abacaxi e de mamão, já que ambos contêm enzimas proteolíticas que podem interferir na absorção dos fármacos. O uso com suco de toranja (uma fruta comum nos EUA) pode aumentar as concentrações de ciclosporina no sangue. Outra recomendação é sua administração em copos de vidro, para prevenir a aderência do medicamento na superfície (o que é comum em caso de uso de copos de material plástico). Nesse caso, deve-se colocar primeiro o diluente (suco), depois a ciclosporina, e misturar imediatamente., 3, 6,7

Outra solução oral disponível são as cápsulas gelatinosas de ciclosporina. Sua vantagem é a fácil administração, uma vez que não é necessário manipular a dosagem do medicamento. Apresenta maior palatabilidade, evita perda de tempo em diluições e é mais fácil de ser aceita pelos pacientes. As cápsulas só devem ser retiradas da embalagem individual imediatamente antes do uso, a fim de manter a estabilidade do princípio ativo. Elas devem ser administradas em intervalos regulares de tempo, uma vez que alimentos interferem na absorção da droga no estômago. Sua absorção pelos pacientes transplantados de fígado é menor, devido à diminuição da produção de bile no pós-operatório. Diferente da ciclosporina, a ingestão oral de cápsulas de tacrolimos não necessita desses cuidados para sua correta administração., ${ }^{2,7}$

O enfermeiro deve ser cauteloso na administração de ciclosporina e de tacrolimos, principalmente quando precisar administrar também outras drogas nefrotóxicas (como anfotericina B, aminoglicosídeos ou cisplatina), a fim de prevenir complicações renais. Quando for necessária a substituição de imunossupressores (por exemplo, tacrolimos pela ciclosporina), deve ser dado um intervalo de 24 horas para administrar o novo fármaco para prevenir o agravamento da nefrotoxicidade. ${ }^{2,7}$

Além desses aspectos, o enfermeiro deve estar atento ao uso de medicamentos que possam aumentar os níveis séricos da ciclosporina e do tacrolimos. Tais medicamentos incluem o verapamil, nicardipina, miconazole, quetoconazol, fluconazol, cimetidina, eritromicina, metilpredinizona, diltiazem e metoclopramide. Esses medicamentos competem com os imunossupressores, por se ligarem a sítios do intestino que levam à diminuição do metabolismo, e, conseqüentemente, ao aumento da absorção dos imunossupressores. Em contrapartida, os medicamentos que podem diminuir os níveis sangüíneos da ciclosporina e do tacrolimos incluem o fenobarbital, 
a fenitoína, a rifampicina e a carbamazepina. Isso ocorre porque tais drogas afetam o sistema do citocromo P-450.?

O enfermeiro atua na monitorização dos níveis séricos dos agentes imunossupressores, uma vez que é a equipe de enfermagem que realiza a administração dos medicamentos e a coleta de sangue para análise laboratorial. Tal informação é essencial para prevenir a rejeição e a toxicidade pelas drogas, já que permite o ajuste da dose pela equipe médica. No caso da ciclosporina, a coleta de sangue pode ser realizada duas horas após a administração da dose, sendo a melhor maneira de se avaliar os níveis da droga no sangue. ${ }^{2,7}$ Vale ressaltar que os protocolos de administração de medicamentos imunossupressores variam entre os diferentes centros transplantadores.

No que se refere aos efeitos colaterais decorrentes do uso desses medicamentos, o enfermeiro deve observar sinais e sintomas indicativos de complicações em casos específicos, como abaixo:

- insuficiência renal: observar alterações dos níveis de uréia e creatinina no sangue; avaliar as características da diurese, como coloração, presença de hematúria e disúria; observar sinais e sintomas de hipercalemia, que incluem fraqueza muscular, depressão do miocárdio, mudanças do eletrocardiograma, cólicas abdominais e diarréia;

- $\quad$ rejeição do enxerto: observar temperatura (febre $>38,3^{\circ} \mathrm{C}$ sem fonte de infecção); quando o dreno de Kher estiver presente, observar diminuição do débito de bile e alterações de suas características: perda de apetite; desconforto abdominal; fadiga; fezes esbranquiçadas; urina escurecida (cor de chá); presença de artralgias e mialgias; presença ou aumento de ascite; elevação das enzimas hepáticas (bilirrubinas, alanina aminotransferase ou ALT, aspartato aminotransferase ou AST e fosfatase alcalina); preparar o paciente para a realização de uma biópsia hepática, preparar o paciente para re-transplante de urgência, caso ocorra rejeição grave;

- hiperplasia gengival: observar presença de alterações na mucosa oral; orientar o paciente a realizar uma boa higiene oral com uso de fio dental e escovação com cerdas macias; encaminhar o paciente para avaliação no dentista para remoção de placa bacteriana; orientar quanto ao uso de antibiótico profilático, antes de qualquer tratamento dentário, conforme prescrição médica (devido ao estado de imunodepressão). ${ }^{7}$

Devido à complexidade relacionada aos cuidados necessários aos pacientes submetidos a transplante de fígado, os estudiosos reforçam a necessidade de prioridades de ensino quanto ao uso de imunossupressores. O enfermeiro deve informar os pacientes sobre os seguintes aspectos: a o descontinuidade do uso de imunossupressores sem consultar seu médico, a importância de ir às consultas médicas, observação de sinais e sintomas de rejeição, monitoramento diário da pressão arterial, monitoramento dos sinais e sintomas de hipercalemia (fraqueza muscular, dor abdominal, diarréia, náuseas, taquicardia), monitorar sinais e sintomas de hipomagnesemia (fraqueza muscular, constipação, íleo paralítico e arritmias cardíacas), evitar a administração de vacinas de vírus vivo, não engravidar e não amamentar durante o uso de agentes imunossupressores, evitar exposição a agentes carcinogênicos conhecidos (sol, cigarro, fumaça, dentre outros), devido ao aumento do risco de desenvolver câncer, manter uma rotina de exames ginecológicos e gastroenterológicos freqüentes. ${ }^{2,6,7,9}$

O uso de medicamentos imunossupressores é vital para o sucesso do transplante de fígado. Estima-se que mais de $80 \%$ dos pacientes desenvolvem algum tipo de rejeição ao longo do período póstransplante, seja aguda ou crônica. A forma mais comum de ocorrência é a aguda, que se manifesta de sete a dez dias após a cirurgia. A forma crônica pode se desenvolver de meses a anos após o transplante. A chave para o tratamento da rejeição é o reconhecimento precoce dos sinais e sintomas e iniciar o tratamento medicamentoso o mais cedo possível.

A combinação da biópsia hepática e dos resultados de exames laboratoriais é a forma mais efetiva para seu diagnóstico. A necessidade de um re-transplante devido a um quadro de rejeição que não responda ao tratamento ocorre em $5 \%$ dos casos. ${ }^{10}$ Uma situação passível de ocorrer relacionada ao uso de medicamentos imunossupressores é a não-adesão dos pacientes ao tratamento. Em 1997 foi publicada uma revisão da literatura que buscou artigos discutindo a adesão de pacientes transplantados aos medicamentos. No que se refere ao transplante de fígado, os autores encontraram que a não-adesão não é freqüente nesses pacientes. Entretanto, ressaltam os fatores de risco para ela, tais como: histórico de abuso de substâncias, idade menor que 30 anos, problemas sociais e econômicos, além de depressão e referem que todos esses fatores estavam relacionados à perda do enxerto por não-adesão. Em pacientes transplantados com histórico de alcoolismo, a recidiva do vício no pós-operatório também está relacionada com a não adesão ao tratamento. ${ }^{11}$

\section{CONCLUSÕES}

A administração de medicamentos no transplante de fígado envolve não somente a administração dos fármacos em si, mas, também um processo de educação em saúde, que permite aos pacientes e familiares a implementação correta da terapia medicamentosa no domicílio com o menor risco possível.

\section{ABSTRACT}

Purpose: Searching for evidences available in the literature concerning the immunosuppressive drugs administration, focusing particularly the nursing care in liver transplantation. Methods: The integrant literature review was the research method used for this study. The internet was employed in order to conduct the electronic search on the MEDLINE and CINAHL databases. The keywords employed were: immunosuppressive agents, nursing care and liver transplantation. Inclusion criteria for selection of articles included studies dealing with immunosuppressive drugs administration on liver transplantation published between 1988 and 2008, in the English, Spanish and Portuguese languages. A sample of eight scientific papers was selected. Results: In addition to drugs administration, the nurse is responsible for the results monitoring, prevention of complications, and patient education regarding the immunosuppressive intake. Cyclosporine and tacrolimus are indicated as prophylactic treatment against rejection of transplanted organs and for chronic rejection treatment. Conclusion: Drugs 
administration in liver transplantation is more than the sole drugs administration, but also a health education process, that allows to patients and their families the adequate implementation of a harmless in-home pharmacological therapy.

Keywords: Nursing Care; Liver Transplantation; Immunosuppressive Agents.

\section{REFERÊNCIAS}

1. Smeltzer CS, Bare BG. Histórico e tratamento de pacientes com distúrbios hepáticos In: Smeltzer CS, Bare BG, editors. Brunner \& Suddarth, tratado de enfermagem médico-cirúrgica. 10a ed. Rio de Janeiro: Guanabara Koogan; 2005. p. 1136-87.

2. O’Donnell M, Parmenter KL. Transplant medications. Crit Care Nurs Clin North Am. 1996;8(3):253-71.

3. Shaefer M, Williams L. Nursing implications of immunosuppression in transplantation. Nurs Clin North Am. 1991; 26(2):291-314.

4. Broome ME. Integrative literature reviews for the development of concepts. In: Rodgers BL, Knafl KA, editors. Concept development in nursing: foundations, techniques and applications. Philadelphia: WB Saunders Company; 2000. p. 231-50.

5. Whittemore R, Knafl K. The integrative review: updated methodology. J Adv Nurs. 2005;52(5):546-53.
6. Giuliano KK, Sims TW. Transplant issues: infections and immunosuppressant drugs. Dimens Crit Care Nurs. 1999; 18(2):16-9.

7. Shultz SL, Meriney DK. Cyclosporine and tacrolimus: a comparison of immunosuppressants used for liver transplantation. Dimens Crit Care Nurs. 1996;15(4):187-97.

8. Taylor RM, Parke A, Day H. Immunosuppression for solid organ transplantation in children. Paediatr Nurs. 2004;16(2):39-43.

9. Armenti VT, Moritz MJ, Davison JM. Drug safety issues in pregnancy following transplantation and immunosuppression: effects and outcomes. Drug Saf. 1998;19(3):219-32.

10. Sheets L. Liver transplantation. Nurs Clin North Am. 1989; 24(4):881-9.

11. Wainwright SP, Gold D. Non-adherence with medications in organ transplant patients: a literature review. J Adv Nursing. 1997;26(5):968-77. 